ALLOPURINOL (AP) INDUCED OROTIDINURIA (ODNU): A TEST OF HETEROZYGOSITY FOR ORNITHINE TRANS692 CARBAMYLASE (OTC) DEFICIENCY. Saul Brusilow \& Dept. of Pediatrics, Baltimore.

In addition to its effects on purine metabolism, In addition to its effects on purine metabolism, AP, via its metabolite, oxipurinol ribonucleotide, inhibits
pyrimidine biosynthesis (PB) at the level of orotidine monophosphate decarboxylase. This inhibition results in increased ODNU. Women heterozygous at the OTC locus have 2 populations of hepatocytes: OTC normal and OTC deficient. We hypothesize that as a consequence of carbamyl phosphate accumulation in the latter cells, $P B$ is chronicaliy increased. inhibition of $P B$ by $A P$ as compared to controls. The AP test increase in oDNo in followed by four pooled includes admintstration of 300mg of AP followed by four pooled consecutive $6 \mathrm{hr}$ urine collections. Urinary orotidine was on a boronate affinity column. We studied 11 control women (C) on a boronate affind heterozygotes (OTCH). The mean (_SEM) peak and 12 oblitionas of $C$ and OTCH was respectively $7.36 \pm 0.46$ (range $5.7-10.1$ ) and $39.7 \pm 7.3$. One $\mathrm{OTCH}$ fell in the normal range (7.71); other OTCH values ranged from 17.9 to 97.9 . Comparison of these results with a protein tolerance test (PTT) administered to the same subjects, shows that the diagnostic sensitivity of the 2 tests are the same and that the same OTCH was negative in both. We conclude that $P B$ that the same oTCH is chronically increased as the PTT, eliminates the risk of hyperammonemia, and is more convenient and acceptabie.

\section{SOUTHEAST ASIA: THE LAND, THE PEOPLE, AND THE} CUSTOMS. Chanthan Chea, Kenneth W. Dumars, Bui Loan,

693 Hanh Nguyen. (Spon. by Thos. L. Nelson) University of Californ

war or religious and ethnic differences has historically resulted in forced migrations. These tragic events do not allow time for planning by either those who must flee for not allow time for planning by either those who must flee for cuted.

The most recent forced migration has resulted in nearly 1 million people migrating to the United States from Vietnam, Laos, milise tho diverse cultures is, at and Cambodia. Thus, and has resulted in misunderstanding in both sectors of the population. For reasons of these cultural differences particularly in the provision of health care, this presentation will address those issues of importance for any medical practitioner caring for patients/clients from Vietnam, Cambodia, or Laos. Actually, the perceived problems are not unique to this or Laos. Actually, the perceived model for any situation which forced migration, but serve as a model for any situation which requires surmounting cultural barriers. In order to provide tial to understand: 1) Heterogeneity of population involved, 2) cultural in this instance health beliefs, of the newly arrived culturat and 3) cultural differences.

An additional presentation will quantify the population differences necessary to provide any special programs for genetic and/ sub-group.

MOLECULAR ANALYSIS OF THE STEROIDOGENIC 11B-HYDRO XYLASE ENZYME Streamson C Chua, Jr, Maria I New,

694 and Perrin C White Cornell University Medical New York, NY.

We have isolated bovine cDNA clones corresponding to a full length mRNA encoding cytochrome $\mathrm{P}-450$ (11BOH), using a short previously described clone (John et al, J Biol Chem 260:5760) and a size-fractionated library enriched for full length $11 \mathrm{BOH}$ CDNA. Sequence analysis shows an open reading frame of 1500 nucleotides which contains the highly conserved heme-binding region and shows $40 \%$ homology to cytochrome $P-450$ (SCC) at amino acid level. The open reading frame contains sequences corresponding to several tryptic peptides of the porcine enzy (J. Shively, pers comm). Several human cDNA clones have been ization analysis with human genomic DNA suggests that the gene is present in a single copy and is about $18 \mathrm{kbp}$. Analys is of genomic ONA from four patients with $11 \beta$-hydroxylase deficiency shows no gross deletions or rearrangements within the structural gene. Hybridization to a panel of somatic cell hybrid cell lines indicates that the gene is on a chromosome distinct from the other steroidogenic P-450 genes (which are on Chr 6, 10, and 15)
MODERATE CHANGES IN PLASMA PHENYLALANINE CONCENTRATIONS AFFECT BRAIN ELECTRICAL DISCHARGE. LOUiS J.

695 Elsas, James F. Trotter, Charles M. Epstein, Philip P. Division of Medical Genetics, Atlanta, Georgia

We previously demonstrated that large changes in blood phenylalanine (phe) concentrations $(500-2000 \mu M)$ decreased plasma L-DOPA, slowed brain electrical discharge and prolonged perfor mance (Ped. Res. 20:112, 1986). In this study we ask whether moderately elevated plasma phe affects brain function. Six heterozygotes for phenylketonuria (PKU) and 2 normal controls were studied in a crossover, blinded protocol of 4,2-week were studied in a crossover, blinded protocol of $4,2-w e e k$
intervals. Volunteers ingested a constant diet of $40-50 \mathrm{mg} / \mathrm{kg} /$ day phe supplemented either with $100 \mathrm{mg} / \mathrm{kg} /$ day phe or placebo. On the last three days of each period the mean power frequency of three electroencephalograms (MPF) were measured. Plasma phe rose in both heterozygotes and controls on ingesting supplemental phe from ancentration of $99+20$ to $140+166 \mu \mathrm{M}$ The range of changes was from -200 to $+400 \mu \bar{M}$. There was an inverse relationship between changes in plasma phe above $50 \mu \mathrm{M}$ inverse relationship between changes in plasma phe above $50 \mu M$
and changes in the MPF. By regression analysis $100 \mu \mathrm{M}$ change in plasma phe produced an inverse change of 0.12 CPS in MPF. We conclude that plasma phe concentrations are raised by phe ingestion in both PKU heterozygotes and homozygous normal, and that alterations in brain electrical discharge are induced by intermediate changes in blood phe concentrations supporting a linear rather than threshold relationship to altered brain function.

CSTEAMINE EYEDROPS DISSOLVE CORNEAL CRYSTALS IN CONG PATINTS WITH NEPHROP ATHIC CYSTINOSIS.

696 w. Juwabara, S. Jain, and M.I. Kalser-Kupfer. Sect1on on tuman Blochem. Gen., NICAD; and Clinical Branch, NEI, Bethesda, MD.

In nephropathic cystinosis, corneal cystine crystals are present by one year of age and increase in density with the crystals are blamed for the photophobia and corneal erosions which plague older patients. We studied the safety and efficacy of eyedrops containing cysteamine, a cystine-depleting agent, in dissolving corneal crystals. First, cystinotic corneal stromal cells, cultured from a penetrating keratoplasty specimen, were depleted of $82 \%$ of their cystine by $1 \mathrm{mM}$ cysteamine within 30 in. Second rablt 3 weeks with exh1bited no toxicity. Third, two cystinotic children $(<2$ years old) recelved cysteamine eyedrops (10 mM, hourly while awake) in a double-masked, placebo controlled trial. Normal saline was put in the opposite eye. In both children, blomicroscopic examination and slit lamp photography documented: a) Bllateral increase of crystals in the cornea between the start of oral cysteamine and the start of the eyedrop protocol; b) Nearly complete clearing of crystals from the cysteamine-treated corneas after 45 months of eyedrops; c) Progression or lack of regression in the 5 months of eyedrops; c) Progression or lack of regression in the corneas not treated with cysteamine. No toxicity was observed, and we are now treating the placebo eyes with cysteamine and enrolling older patients. This represents the first in vivo demonstration of crystal dissolution by cysteamine in cystinosis, and suggests that oral cysteamine, if adequately delivered to target tissues, might dissolve crystals in other cystinotic organs also.

NONRENAL COMPLICATIONS OR NEPHROPATHIC CYSTLNOS IS AFTER RENAL FAILURE. W.A. Ggh1, M. 1 . Kalser-Kupfer,

697 and J.K. FInk. Section On Human HICDS, NIH, Bethesda, ND.

He examined 15 patients with nephropathic cystinosis age 13-27 years. One 15-year-old o1rl had recelved peritoneal dialysis for $31 / 2$ years; the others each recelved an initial renal allograft between 7 and 13 years of age. All 15 patients had photophobia and episodes of corneal erosion. These were at had photophoblating in 4 patients; one 13-year-old boy recelved times incapacitating in 4 patients; one 13-year-old performed substantial relief from a penties falled to offer rellef. Five after other treatment modalities falled to offer rellef. patients had markedly decreased uncorrectable visual aculty, posterfor synechlae and crystal deposition on the lens surface. Four had color vision deficits; 3 had elevated dark adaptation. Electroretinography supported these findings. All 15 patients were growth retarded, with mean helght age $8.9+3.8$ (SD) years less than chronological age. Bone age was also far behind chronological age. Sexual development was delayed, but usually com plete by 17 years of age. Hepatic function appeared normal. Nine patients required thyroid replacement. One patient had neurological 1mpairment with bradykinesia, dementla, dysarthria and dysphagla. S1x patients, all asymptomatic, had significant cerebral atrophy on CT scan, and. two had deep white matter calc1fications. Recently, oral cysteamine therapy has been shown help prevent renal deterioration and lmprove growth ln young children with cystinosis. The extensive nonrenal involvement in longstanding cystinosis suggests that this cystine-dep agent should be cons 